\title{
Sliding wear analysis of cobalt based alloys in nuclear reactor conditions
}

\author{
Ruby McCarron*1, David Stewart ${ }^{2}$, Philip Shipway ${ }^{3}$, Daniele Dini ${ }^{1}$ \\ ${ }^{1}$ Tribology Group, Department of Mechanical Engineering, Imperial College London, South \\ Kensington Campus, Exhibition Road, London SW7 2AZ, UK \\ ${ }^{2}$ Rolls-Royce, Derby, UK \\ ${ }^{3}$ School of Mechanical, Materials and Manufacturing Engineering, University of Nottingham, \\ University Park, Nottingham, NG7 2RD, UK \\ *Corresponding author: r.mccarron14@imperial.ac.uk
}

\section{Abstract}

The study of the wear behaviour of cobalt based alloys in nuclear reactor environmental conditions is the focus of this work. The alloys are used in components within reactors due to their excellent wear and corrosion resistance and their high hardness in the high pressure and temperature water facing environment. In the nuclear reactor core, cobalt is irradiated producing a highly penetrative gamma emitting isotope, cobalt 60 from stable cobalt 59 . Wear of the cobalt alloys, producing wear debris, exacerbates this problem as it may be transported and deposited at various locations throughout the primary loop increasing the potential of radiation exposure. Removing this problem will require the removal of cobalt from the system.

In order for suitable replacement materials to be identified, a better understanding of the behaviour of these alloys in the prototypical working conditions must be obtained. This work focuses on two cobalt based alloys used in the ball and race components of rolling element bearings in the reactor core, Stellite 20 and Haynes 25, respectively. The sliding wear behaviour of the alloys in an environment designed to replicate reactor conditions is examined using a bespoke pin on disc tribometer. Wear measurement and microstructural and compositional analysis of the samples tested over a range of conditions are presented and discussed.

Concurrent to the experimental work is the development of a wear prediction model using a semi analytical method. The model employs Archard's wear law as the method of predicting wear using data obtained through experimentation. The accuracy of the semi analytical model is limited however it does give a good estimation for maximum wear depth of the test specimens.

Keywords: Sliding wear; cobalt-based alloys; contact mechanics; pin on disc; wear prediction;

\subsection{Introduction}

Cobalt-based alloys offer very good resistance to wear and chemical corrosion, and, thanks to their exceptional properties in water lubricated environments, they are often used in different bearing surfaces in nuclear applications. In reactor environments, stable cobalt-59 is bombarded with thermal neutrons producing a radioactive isotope cobalt-60 [1]. Cobalt-60 has a relatively long half-life of 5.3 years and is a penetrative gamma emitter. Wear debris generated in bearings containing cobalt-60 is transported, suspended in the coolant, becoming deposited at locations around the loop. Exposure to cobalt-60 containing wear debris, produced due to different wear mechanisms, is a leading contributor to occupational radiation exposure of maintenance personnel [2]. 
Therefore, in order to reduce exposure to these isotopes, a leading contributor to occupational radiation exposure, there is a trend to reduce and ultimately remove cobalt based materials to facilitate decommissioning. It is necessary to find an alternative to cobalt based alloys which has suitable tribological properties in water; this can only be achieved by exploring the tribological behaviour of these alloys for bearing applications in more detail and unravelling the mechanisms responsible for their superior performance so that they can be mimicked using Co-free alloys.

The excellent oxidation and corrosion resistance of cobalt-based alloys have made them ideal candidates for application in extreme environments, as already observed by the survey produced by Amateau and Glaeser in the early ' 60 s [3] on the selection of bearing materials for high temperatures. These alloys are widely used in high temperature engineering applications as their resistance to wear and corrosion is often paired to their maintenance of strength at elevated temperatures [4]. These favourable characteristics are attributed to a number of factors. Chromium, tungsten and molybdenum contribute to the solid solution strengthening of the alloys. Chromium also contributes to the corrosion resistance with tungsten promoting the high hardness of the alloys. The oxidation behaviour and the resistance of alloys to deformation are the main reasons behind their excellent wear performance [4].

In the past decades the use of cobalt-based alloys as bearing material has been widely accepted and a number of examples can be found in the literature where researchers have been investigating friction and wear properties of such materials in severe testing conditions (see e.g. [5-17]). In particular, an interesting review of the level of understanding of the elevated temperature wear resistance of various metals and alloys, including many Co-based materials, was reported by Pauschitz and co-workers [10]. The formation of a "glaze" under different alloying, temperature and sliding conditions was identified as a salient feature in a systematic review of all results reported in the recent literature. Different classifications of the "glaze" formed on the surface of metal components that underwent sliding wear tests in elevated temperatures are identified either as transfer layers, mechanically mixed layers and composite layers. Scenarios where no layer was formed were also mentioned but it was indicated that most studies reviewed, identified the formation of a layer, its classification depending on the salient features mentioned above. The comparative chemical composition of the wearing and mating surfaces versus that of the worn surface are described as identifying features for each classification. It is pointed out that in the case of the transfer and mechanically mixed layers the oxygen content of the worn surface is low where as a high oxygen content is anticipated in the presence of a composite layer. The wear conditions of the test will also influence how these layers are formed. A series of studies was also conducted by Yu, Amhed and co-workers [15, 16, 18] to study the influence of manufacturing process and alloying element content on the tribomechanical properties of cobalt-based alloys. The aim was to comprehend the structure-property relationships of a wear resistant cobaltbased alloys (Stellite 20 and Stellite 6) produced from two different processing routes of powder consolidated and hot isostatic pressing (HIPing) and casting. Microstructural and tribomechanical evaluations, which involved hardness, impact toughness, abrasive wear, sliding wear, and contact fatigue performance tests, indicated that despite the similar abrasive and sliding wear resistance of the two pair of alloys, the HIPed alloys exhibited an improved contact fatigue and impact toughness performance in comparison to the cast counterparts The effect of re-HIPing was also recently studied [18]. More recent investigations focused on the in-service wear mechanisms and cross-sectional microstructural evolution of Stellite 6 cobalt-based alloys subjected to sliding contact conditions using focused ion beam (FIB), transmission electron microscopy (TEM), nano-indentation and nanoscratching techniques $[5,12]$. 
Of particular interest for this paper is the material used for Rolling Element Bearings (REBs), which are used in the primary loop of nuclear reactors allowing the movement of key structural components. These bearings are lubricated by the coolant water that is circulated in the primary loop. The alloys from which the bearings are made must be able to operate in this high pressure and temperature water, $12 \mathrm{MPa}$ and $310^{\circ} \mathrm{C}$ respectively [19], as well as being corrosion resistant. This environment will be influential to the mechanical and electrochemical factors leading to wear of the bearings. Theoretically, a REB that is in a state of pure rolling should be completely unaffected by wear. In most applications, however, the bearings are not in a perpetual state of rolling and will be exposed to factors leading to mechanical wear such as slip, entry of abrasive particles in the system, a poor lubrication regime or system vibrations while the bearing is at rest and unlubricated, both leading to wear through raceway to rolling element contact [20]. The mechanisms that manifest in the wear of REBs will vary and may involve adhesive, abrasive, fatigue, corrosive wear or a combination of several such mechanisms [21].As mentioned, it is unlikely that pure rolling will be exhibited in the REB system. [22] discusses the manifestation of local sliding as a result of slip in the rolling contact, in this case the ball/race contact, concluding that the majority of rolling contacts are in reality 'rolling/sliding' contacts. Sliding wear, like rolling wear, is complex and may be manifested by a number of mechanisms, including those listed above. The complexity of the mechanism and the relative simplicity of performing sliding wear tests have resulted in extensive work on the different mechanisms governing this phenomenon [23].

The materials selected for use in these REBs must exhibit excellent resistance to both mechanical and electrochemical wear in the prescribed environmental conditions. The reliability of all components within the reactor will be key to its overall safety performance [2]. Two such alloys used in the ball and race components of these REBs are Stellite 20 and Haynes 25 respectively, each composed of approximately 50\% cobalt.

As mentioned above, to replace the cobalt alloys, alternative alloys must be selected. Any alternative alloy must exhibit the same wear behaviour demonstrated by Stellite 20 and Haynes 25, which implies the requirement for a detailed assessment and qualification study [2].

The first step in identifying a suitable alternative is to gain an in depth understanding of the mechanical and electrochemical behaviour of Stellite 20 and Haynes 25 in conditions designed to replicate the reactor environment, which is the focus of the present article.

This process is initiated with experiments examining the sliding wear behaviour of the alloys in a set up and environment designed to replicate reactor conditions. The conditions chosen are based on literature [19] and normal operating condition dictated by in-service loading experienced in reactor environments, adapting this to meet the capability of the experimental apparatus developed at the University of Nottingham and presented for the first time in this paper.

Another important aspect of the work is the assessment of the predictive capabilities of different models in terms of wear scar and wear volume. A semi-analytical wear prediction model has been developed based on work presented in the literature [24]. The advantage of this model is that it is far less computationally expensive compared to other methods such as finite element modelling (FEM). This is because rather than computing wear for each surface node of a finely applied mesh in each sliding increment, the semi-analytical model determines a 'global' wear loss figure which calculates one value for material wear depth over each sliding increment. A limitation of the semi-analytical model is that while the wear coefficient value used will be influenced by the test environment, different aspects that may affect the wear process will be overlooked such as the growth/destruction of any protective oxides on the component surface or change in the rate of wear as one wear mechanism evolves 
to another [25]. Furthermore, the semi-analytical results are limited by the Hertz approximation which hardly holds when the contact size becomes comparable to the disc thickness and oxide layers are explicitly introduced. However, there is scope to address this in future work using FEM which would allow the incorporation of variables beyond a mechanical interaction between two smooth, clean surfaces.

The current work focusses on the wear measurements for the sliding wear experiments. After describing the development of the test set up and the operating conditions, microstructural and compositional analysis of the test components which underwent the most severe wear are presented and compared The semi analytical wear prediction models employed by the authors is described and presented comparing wear depth of the test components at all test conditions. The work performed by the authors sheds light on important aspects of the wear mechanisms experienced by Stellite 20 and Haynes 25 and provided an overview of modelling techniques that can be used as design tools for the development of new materials to replace these cobalt-based alloys.

\subsection{Materials and Methods}

\subsection{Materials}

Stellite 20 is a two phase metal alloy known for its high hardness and excellent resistance to wear and corrosion at elevated temperatures. Figure 1, below, presents the microstructure of an undamaged surface area of a Stellite 20 ball used in these experiments. The dark grey chromium rich carbides and the white tungsten rich carbides are clearly identified in the micrograph. The medium/light grey portion is a cobalt chromium tungsten rich matrix in which these carbides are suspended.

Haynes 25 is a ductile, corrosion resistant alloy with excellent high temperature strength [26]. The microstructure of Haynes 25 is generally a single phase face centre cubic system. This may be evolved by the application of mechanical work and temperature treatment [26]. These treatments result in the precipitation of carbides and other phases in the microstructure, while imparting ductility on the alloy. The manufacturer provided nominal composition of Stellite 20 and Haynes 25 are presented in Table 1.

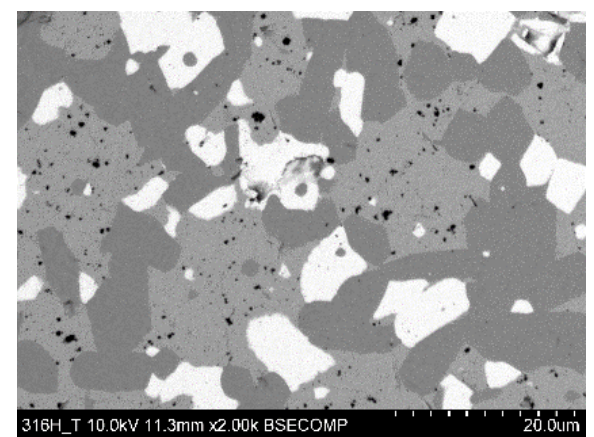

Figure 1: Microstructure of an undamaged Stellite 20 ball

\begin{tabular}{|l|l|l|l|l|l|l|l|l|}
\hline \%wt & $\mathbf{C o}$ & $\mathbf{N i}$ & $\mathbf{C r}$ & $\mathbf{W}$ & $\mathbf{F e}$ & $\mathbf{M n}$ & $\mathbf{S i}$ & $\mathbf{C}$ \\
\hline Stellite 20 & Balance & $3 * *$ & $30-34$ & 13 & $3 *$ & $0.5 *$ & $1 *$ & $2.8-3$ \\
\hline Haynes 25 & Balance & 10 & 20 & 15 & $3 *$ & 1.5 & $0.4 *$ & 0.1 \\
\hline
\end{tabular}

*= Maximum

Table 1: Material composition

The $9.525 \mathrm{~mm}$ diameter balls were purchased from RGP Balls, Milan. The hardness of the Stellite 20 balls as per the technical data sheet provided by RGP Balls was 56-63 HRC (612-775 HV).The discs were cut from a block 
of Haynes 25 provided by Rolls Royce in cold worked form. The sample was aged at $605{ }^{\circ} \mathrm{C}\left(+/-5^{\circ} \mathrm{C}\right)$ for 6 hours in an uncontrolled atmosphere and cooled naturally in air. The approximate hardness of the block after ageing was measured to be $570 \mathrm{Hv} 30$. The $30 \mathrm{~mm}$ diameter discs were machined from the block and polished to $0.8 \mu \mathrm{m}$.

\subsection{Ball on disc test}

A bespoke design ball on disc tribometer at the University of Nottingham was used examine the wear behaviour of the Stellite 20 ball and Haynes 25 disc. The $9.525 \mathrm{~mm}$ diameter ball was held in place, exerting a normal load on the $30 \mathrm{~mm} \times 10 \mathrm{~mm}$ disc, held in the disc carrier and rotated via a shaft as can be seen in the schematic in Figure 2.

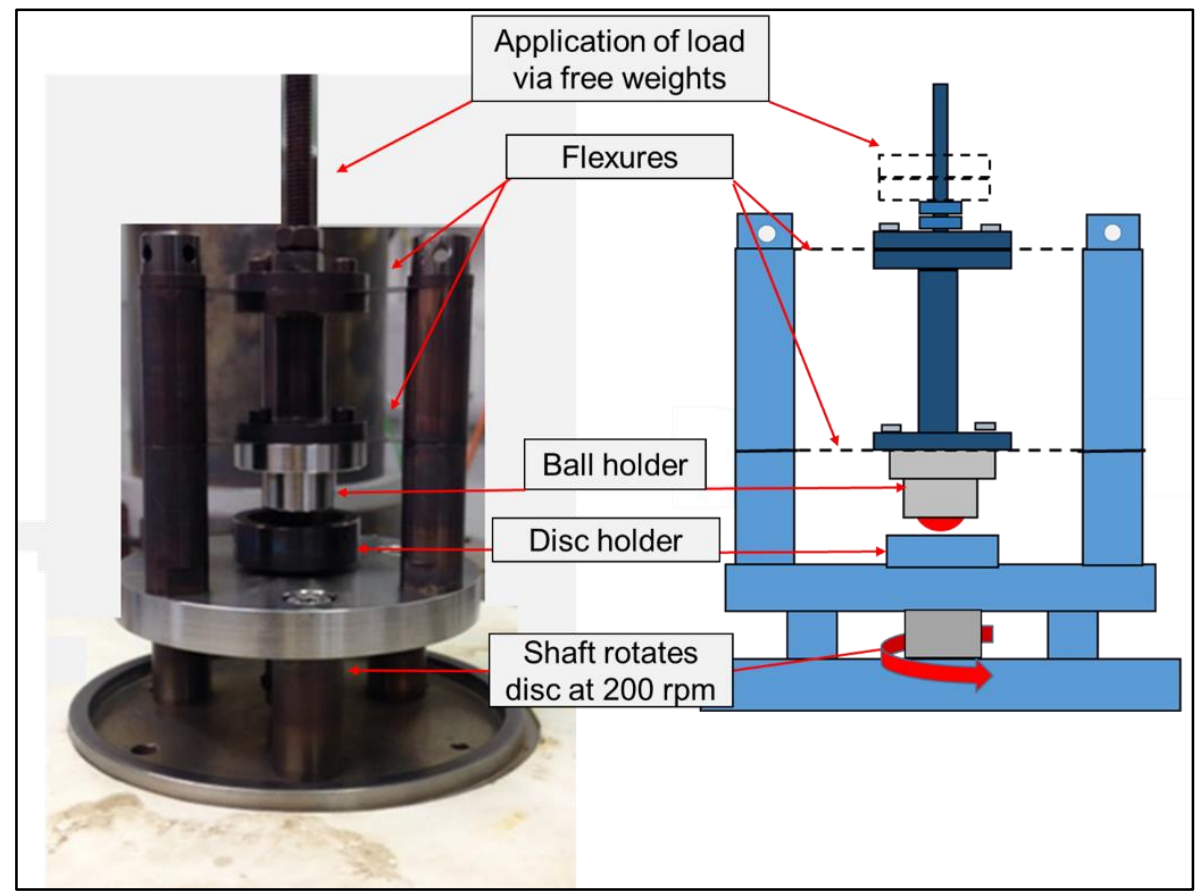

Figure 2 Pin on disc tribometer developed at the University of Nottingham adapted to accommodate a Stellite 20 ball as a pin in the sliding wear test configuration.

The rig is enclosed in an autoclave allowing for experiments at elevated temperatures, ranging from room temperature $\left(20^{\circ} \mathrm{C}\right)$ to $250^{\circ} \mathrm{C}$. Fluid (solution of $10 \% \mathrm{Li}-\mathrm{OH}$ in distilled water) mimics the coolant in the relevant nuclear reactor loop and is circulated in the autoclave via a mechanical pump.

Experiments can be performed under a normal load from $0 \mathrm{~N}$ to $35 \mathrm{~N}$ applied by free weights as also shown in the schematic in Figure 2. Table 2 lists the conditions for each test. Each test was performed once as this is a preliminary investigation on the wear mechanisms experienced in different conditions and will lead to a more extensive test matrix to be carried out in the future. 


\begin{tabular}{|l|l|l|l|l|l|l|}
\hline Test Setup & Description \\
\hline Time & 180 minutes \\
\hline Speed & 200 rpm \\
\hline Sliding distance & $2295.95 \mathrm{~m}$ \\
\hline Test conditions & \multicolumn{6}{l|}{ Test number } \\
\hline & 1 & 2 & 3 & 4 & 5 & 6 \\
\hline Normal load $[\mathrm{N}]$ & 10 & 10 & 10 & 35 & 35 & 35 \\
\hline Temperature $\left[{ }^{\circ} \mathrm{C}\right]$ & 20 & 100 & 200 & 20 & 100 & 200 \\
\hline
\end{tabular}

Table 2: Test conditions

\subsection{Post-test analysis method}

\subsubsection{Microstructural and compositional analysis}

The secondary (SE) and backscattered electron (BSE) modes of a Hitachi S-3400N scanning electron microscope (SEM) were used to examine the impact of the wear tests on the surface and subsurface of the test components. The energy dispersive X-ray (EDX) mode on the SEM was used for elemental analysis of the samples.

\subsubsection{Wear measurement}

A micrograph was taken of each ball scar and the approximate diameter measured.

Equation 1 was used to measure the volume lost by the ball:

$\boldsymbol{V}=\pi \boldsymbol{h}^{2}\left[\boldsymbol{R}-\frac{\boldsymbol{h}}{3}\right] \quad$ and $\quad \boldsymbol{h}=\boldsymbol{R}-\sqrt{\boldsymbol{R}^{2}-\boldsymbol{r}^{2}} \quad$ Equation 1 (a) and (b) [27]

where $V$ is the volume of material lost, $h$ is the maximum wear depth, $R$ is the ball radius and $r$ is the radius of wear scar, as schematically depicted in Figure 3.

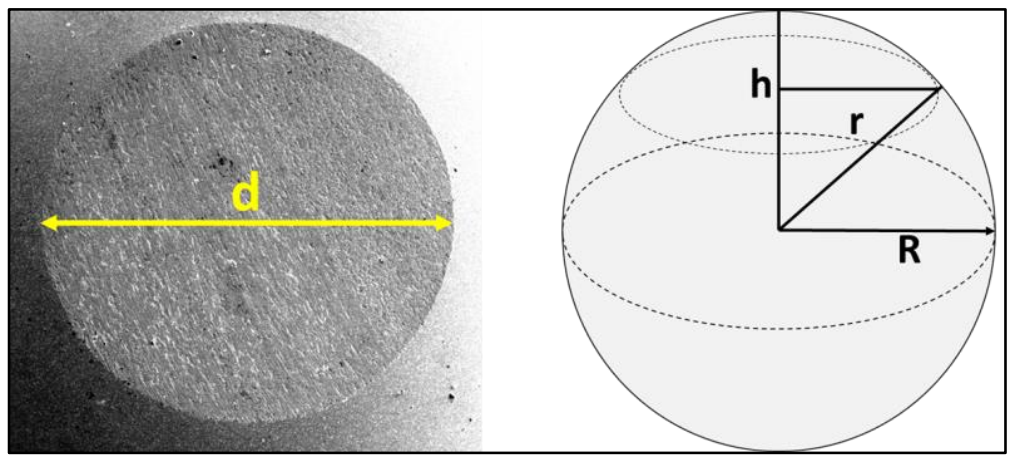

Figure 3 (a) Micrograph of a scar produced on Stellite 20 ball after sliding experiment and (b) schematic of ball used to describe volume loss calculation

A VEECO WYCO white light interferometer was used to measure the volume loss from the disc by measuring the average wear track profile at several points along the scar and using geometry to calculate the total volume lost [28]. The wear coefficients for the contact pair in each test is then calculated using Archard's wear law, which is described in section 2.4 . 


\subsection{Wear quantification and prediction}

Archard's wear law, equation 2, is used extensively throughout the literature describing the relationship between the material wear volume lost in a sliding interaction, load applied, sliding distance and material hardness [22]:

$\boldsymbol{V}=\frac{\boldsymbol{k F s}}{\boldsymbol{H}}$

Equation 2

where $V$ is the volume of material removed, $k$ is the wear coefficient, $F$ is the applied normal force, $s$ is the sliding distance and $H$ is the hardness of the softer material. The wear coefficient $k$ is an experimentally obtained coefficient in the wear law that is specific to the parameters and environment of each test. In this investigation, wear of both test components was observed and a wear coefficient is therefore obtained for each component. The implementation of a successful wear prediction model would greatly reduce the need for complicated and expensive environmentally-appropriate material and component validation rigs. In the following sections the modelling strategy is implemented and discussed in the context of the experimental tests conducted by the authors.

\subsubsection{Semi analytical model}

The semi analytical wear model is built using information presented in [22], to which the interested reader should refer to obtain the details to perform the full implementation of the method. The model uses a combination of Hertzian contact mechanics [29] and Archard's wear law to calculate the wear over a sliding increment.

The component geometry, material properties, applied normal load and the experimentally obtained wear coefficient- see table 3- are entered into the model. The total sliding distance is divided into increments according to the length of the disc wear track i.e. one sliding increment is equal to the length of the track per one revolution. For each sliding increment the data entered are applied to the relevant contact and wear equations and wear depth is calculated for the relevant test component within that increment. At the end of the iteration, the component geometry is updated according to the wear depth calculated and the cycle begins again. This continues until the final sliding distance is reached.

The model can be used to present a visualisation of the changing contact area and as a result, the contact pressure of the interaction due to the progression of wear and changing component geometry.

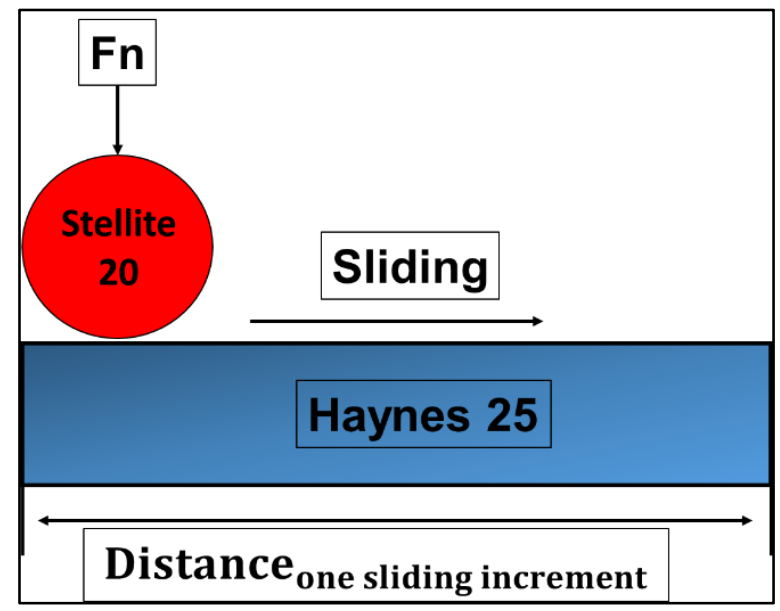

Figure 4: Schematic of set up of the semi analytical model. Hertzian geometry is used for a sphere on flat (point contact) 


\subsection{Results and Discussion}

\subsection{Wear of ball and disc}

Figures 5, 6 and 7 below show the results for the three temperatures tested. Images of ball wear scars and disc wear tracks are reported for each experimental test with the corresponding disc wear track profiles for $10 \mathrm{~N}$ and $35 \mathrm{~N}$ loads. In figures 5 and 6 (a) and (c) the evolution of wear on the ball surface from uneven damage to a distinctive, clear scar can be followed from the $10 \mathrm{~N}$ load to the higher, $35 \mathrm{~N}$ load. At $200^{\circ} \mathrm{C}$, where the wear to the ball surface increased significantly at both loads, this evolution does not seem as pronounced. The scar radius has increased rather than changing shape, perhaps implying more uniform wear of the ball surface earlier in the interaction. This is likely to be due to a reduction in the wear resistance of the Stellite 20 ball in the highest temperature. Figures 5, 6 and 7 (b) and (d), produced using the white light interferometer, show a clear increase in the width of the disc track with increasing temperature and load. The topographical evolution of wear is interesting. At the most conservative test conditions, see figure 5 (b), the track appears smooth. As load and temperature increase, grooves within the tracks appear implying a corresponding increase in wear.

As can be seen, under the $10 \mathrm{~N}$ load, as temperature increases, the width of the track increases. The depth of the track for this loading condition increases with an increase in temperature from $20^{\circ} \mathrm{C}$ to $100^{\circ} \mathrm{C}$. At $200^{\circ} \mathrm{C}$ the change in track depth is not significant when compared to the $100^{\circ} \mathrm{C}$ test. The track widths also increase with temperature for the $35 \mathrm{~N}$ tested discs. However, the wear depth follows a different trend than that observed for the $10 \mathrm{~N}$ tests in that as the temperature increases the profile of the track becomes shallower.

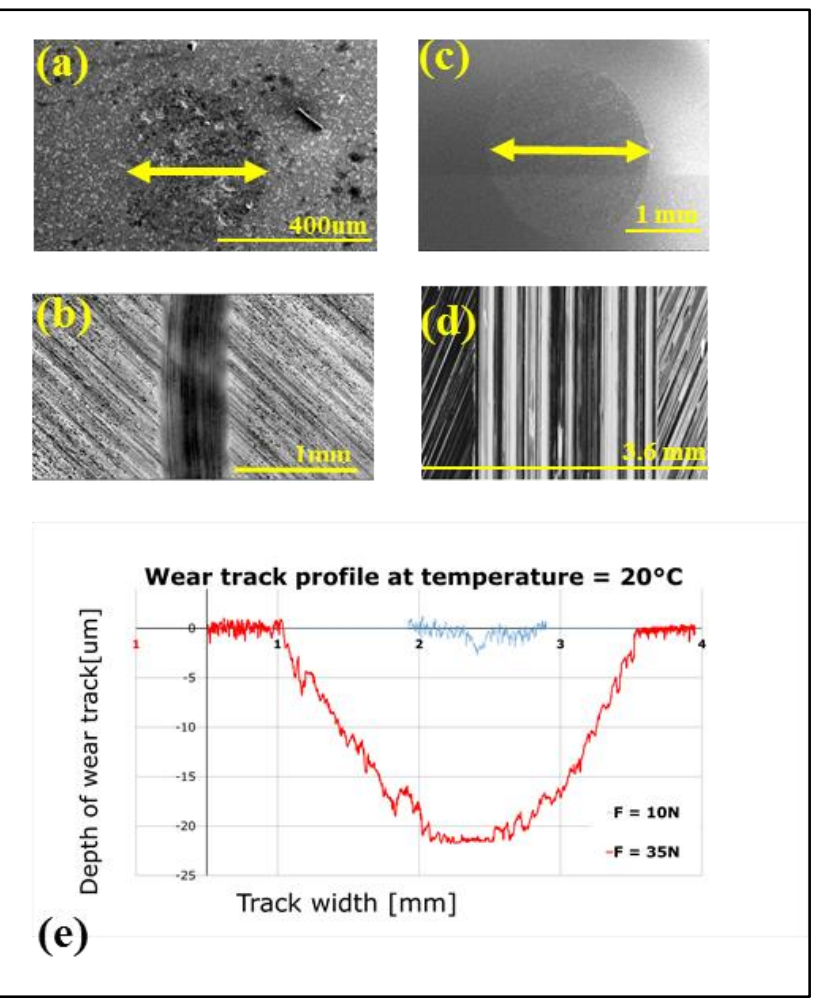

Figure 5: ball and disc wear scar and track under (a) and (b) $10 \mathrm{~N}$ and (c) and (d) $35 \mathrm{~N} l o a d s$ in $20^{\circ} \mathrm{C}$ test (e) represents profile of the disc wear tracks produced under each load 


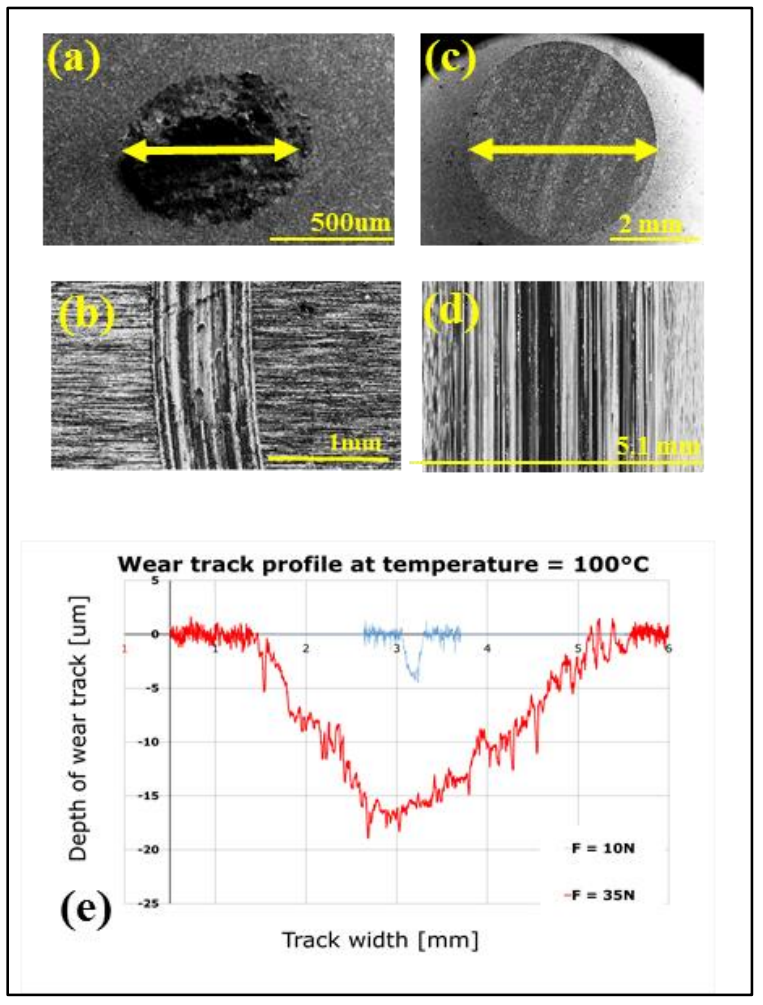

Figure 6: ball and disc wear scar and track under (a) and (b) $10 \mathrm{~N}$ and (c) and (d) $35 \mathrm{~N}$ loads in $100^{\circ} \mathrm{C}$ test (e) represents profile of the disc wear tracks produced under each load

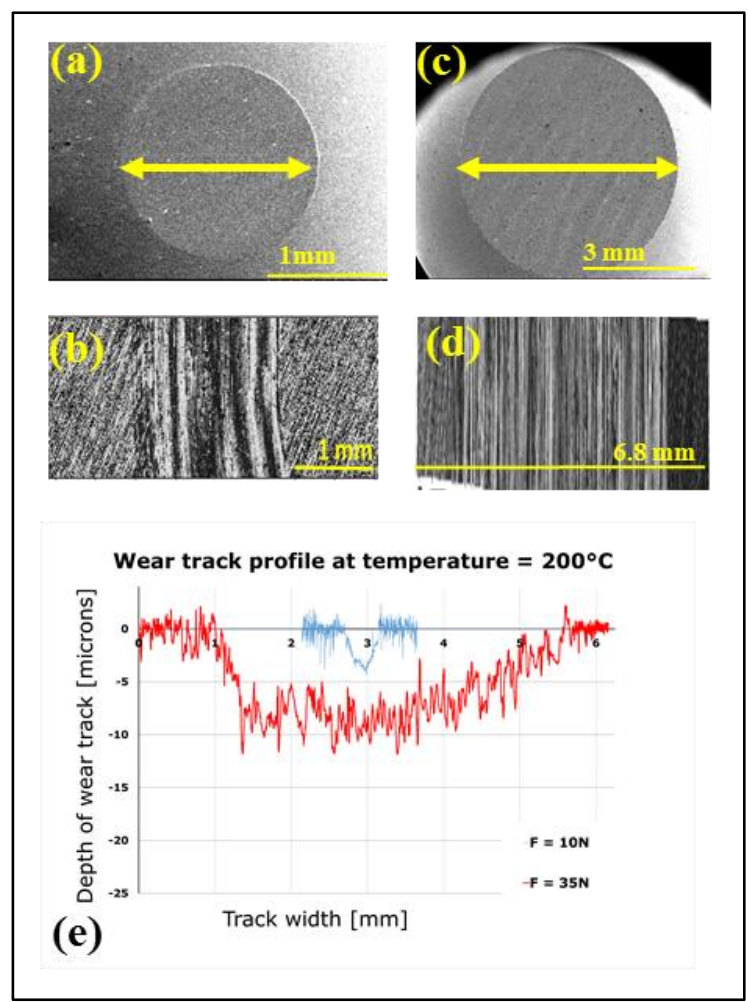

Figure 7: ball and disc wear scar and track under (a) and (b) $10 \mathrm{~N}$ and (c) and (d) $35 \mathrm{~N}$ loads in $200^{\circ} \mathrm{C}$ test (e) represents profile of the disc wear tracks produced under each load 


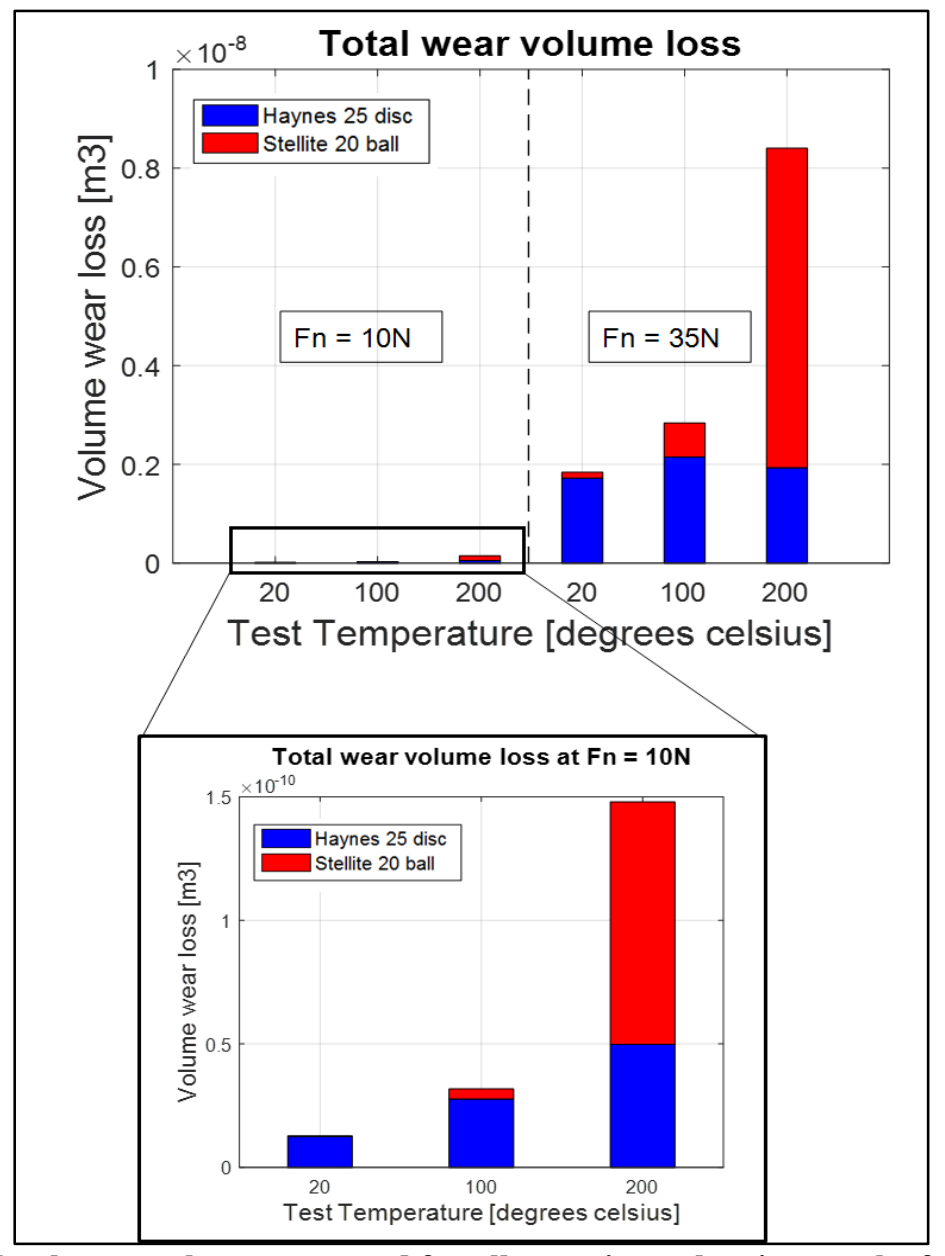

Figure 8: Total wear volume measured for all tests; inset showing results for $10 \mathrm{~N}$ tests

Figure 8 illustrates the total material volume lost as a result of sliding wear measured; the top portion of each bar representing the ball wear and the bottom the disc wear. The wear under the lower applied load can be seen more clearly in the inset to Figure 8. As expected, with an increase in temperature and applied load, a significant increase in total wear volume is observed. The wear volume measured for the $10 \mathrm{~N}$ tests increases with increased temperature, rising significantly at $200^{\circ} \mathrm{C}$. At room temperature, there is negligible wear of the Stellite 20 ball, not unusual as this is the harder of the two materials. A notable increase in wear of the Stellite 20 ball is seen at the higher temperature for both tests, implying a reduction in the wear resistance of the Stellite 20 ball at $200^{\circ} \mathrm{C}$ - this is more significant than the reduction seen at $100^{\circ} \mathrm{C}$. This might be due to the evolution of the microstructure, which can be seen in the images of the ball scar in figures 9-11 (c) and (d). As the hard, tungsten rich carbide is damaged, the alloy may become weaker.

When looking at the wear volume under the $35 \mathrm{~N}$ load, a different pattern is observed. Wear of the Stellite 20 ball increases significantly with increasing temperature as before. The disc wear volume measured does not follow this pattern. At $20^{\circ} \mathrm{C}$, the lowest disc wear volume temperature range under the higher loading condition was measured. In $100^{\circ} \mathrm{C}$, the wear measured increases slightly, although not as significantly as the increase in ball wear. In $200^{\circ} \mathrm{C}$, the disc wear volume decreases, although relative to the difference in ball wear volume over the temperature range, the difference is not significant.

This is likely to be linked to the interplay between different wear mechanisms, namely the evolution of microstructure and consequential reduction of wear resistance of the Stellite 20 ball at higher temperatures and 
the changes in response of Haynes 25 in higher loading conditions, as this is an alloy known for its susceptibility to work hardening [30]. As the hardness of the Haynes 25 disc increases when the larger load is applied and plasticity is more likely to occur during loading, the component becomes more resistant to material removal from the sliding interaction. The simultaneous deterioration of the wear resistance of Stellite 20 results in increased wear rate for the ball. This in turn causes a change in the contact area and increases the width of the wear track, and consequently lowers the contact pressure during the experiments. To be more specific, under the higher loading conditions tested here, a significant increase in material wear of the Stellite 20 ball was observed (see Figure 8). This is also apparent in the micrographs of the ball scars presented in figures 5, 6 and 7 (a) and (c). This has an impact on the shape of the ball, i.e. as wear of the ball increases the contact area becomes "flatter" and the pressure distribution between the two bodies conforms; this process happens more rapidly as the temperature increases. The contact area increases as a result of this process and the average contact pressure decreases accordingly. The reduced material wear volume of the disc may be attributed to this considering the linear relationship of wear volume and pressure in Archard's wear equation. This is however linked to the evolution of the system during the tests and further tests, interrupted at different sliding distances, may help shedding light on the time-dependent response of this material pair.

The material wear volume measured for the components in each test condition are applied to Archard's wear law (equation 2), and the wear coefficient is calculated, see table 3 .

\begin{tabular}{|c|c|c|c|c|}
\hline & $\begin{array}{l}\text { Diameter } \\
{[\mathrm{mm}]}\end{array}$ & $\begin{array}{l}\text { Depth } \\
{[\mathrm{mm}]}\end{array}$ & Hardness [Hv] & $\begin{array}{c}\text { Young's } \\
\text { modulus [GPa] }\end{array}$ \\
\hline Stellite 20 ball & 9.525 & & 649-867 & 257 \\
\hline Haynes 25 disc & 30 & 10 & 572 & 225 \\
\hline & $\begin{array}{c}\text { Test } \\
\text { Load }[N]\end{array}$ & $\begin{array}{c}\text { Test Temperature } \\
{\left[{ }^{\circ} \mathbf{C}\right]}\end{array}$ & $\begin{array}{c}\text { Wear coefficient } \\
\text { (ball) }\end{array}$ & $\begin{array}{l}\text { Wear coefficient } \\
\text { (disc) }\end{array}$ \\
\hline Sample 1 & 10 & 20 & $8.281 \mathrm{E}-15$ & $3.078 \mathrm{E}-13$ \\
\hline Sample 2 & 10 & 100 & $1.006 \mathrm{E}-13$ & $6.898 \mathrm{E}-13$ \\
\hline Sample 3 & 10 & 200 & $2.447 \mathrm{E}-12$ & $1.239 \mathrm{E}-12$ \\
\hline Sample 4 & 35 & 20 & $2.648 \mathrm{E}-12$ & $1.22 \mathrm{E}-11$ \\
\hline Sample 5 & 35 & 100 & $1.901 \mathrm{E}-11$ & $1.525 \mathrm{E}-11$ \\
\hline Sample 6 & 35 & 200 & $6.100 \mathrm{E}-11$ & $1.373 \mathrm{E}-11$ \\
\hline
\end{tabular}

Table 3: Ball and disc component information, wear coefficient calculated using experimental data and Archard's wear law for each test condition.

\subsection{Microstructural and compositional analysis}

A distinctive transfer layer across surface of the track is seen in figure 9 (a) and (b). EDX analysis of this layer revealed increased levels of oxygen and carbon not seen in a bulk analysis of the area. Figures 9 (c) and (d) highlight the border between the clean ball and the scar. The change in microstructure between the two is obvious. In feature 1 in figures (c) and (d), the different phases have not been completely altered, damage is at the point of initiation. Feature 2 in figure 9 (c) and (d) highlights what might be cracking and surface damage of the ball surface. The sliding interaction initially induces changes of the surface and alteration of the microstructure giving it a smoother appearance. In feature 2 in figure 9 (c) and (d) the distinct phases can no longer be identified. It seems that the surface is cracking as wear is progressing. EDX analysis of this, and other similar features in the ball scar revealed a significant level of oxygen ( $29 \%$ weight), an element not present in analysis of a clean area 
of the tested ball, which suggests that oxidation is taking place. Smooth material removal from the disc surface is represented by the shallow, even grooves and scratches seen in figures 9 (a) and (b). Analysis of points within these scratches revealed notable levels of carbon at levels not seen over the entire scar area. EDX analysis of this area revealed levels of nickel. The presence of nickel implies material transfer and perhaps adhesion from the disc track to ball scar is occurring.

Figures 10 (a) and (b) present a grooved track, the grooves appearing slightly deeper than the scratches observed in figures 9 (a) and (b). A corresponding pattern is seen on the ball scar - see figure 10 (c). EDX analysis within the disc track grooves found a slight increase in carbon although an increase in oxygen was not seen as in the $20^{\circ} \mathrm{C}$ test. The topographical damage highlighted in feature 1 within the disc wear track is a recurring feature observed over the entire track implying that material is not being ploughed as uniformly as during the $20^{\circ} \mathrm{C}$ test. Once again a transfer layer dispersed over the track surface is visible albeit appearing less frequently, having a similar composition to that seen in figure 9 (a) and (b).

The track produced on the surface of the disc sample tested at $200^{\circ} \mathrm{C}$ once again features the same grooved appearance as the $100^{\circ} \mathrm{C}$ test. Topographical damage similar to that observed in feature 1 of figure 10 (a) and (b) is also seen across the track, see figure 11 (a) and (b). The presence of a transfer layer is not as clearly shown on the surface as for the lower temperature discs. It can, however, still be observed in small, less densely distributed areas. EDX analysis did reveal that these small regions were of a similar composition as on the previous samples. In figure 11 (c) and (d) the area of the scar presented appears even with a grooved appearance as in figure 10 (c) and (d), the grooves in the direction of sliding, and corresponding to the topography of the disc track surface.

The observations made through microstructural and compositional analysis agree with the material loss measurements. At $20^{\circ} \mathrm{C}$, where the lowest wear volume was measured for both the ball and disc in the higher loading condition, the surfaces of both components presented with the least amount of surface damage. The disc track did not feature the topographical damage as seen at the higher temperature tests, see feature 1 in figures 10 and 11 (a) and (b). The two phase microstructure of the Stellite 20 ball is also more easily identified in the backscattered electron microscope images than for the $100^{\circ} \mathrm{C}$ and $200^{\circ} \mathrm{C}$ conditions.

The comparable microstructural and topographical analysis of the disc surfaces in figures 10 and 11 (a) and (b) correspond to the wear volumes measured for these components, for which a significant difference in volume was not observed. There is also a relationship between the evolving microstructure observed within the Stellite 20 ball scar and the changing rate of wear. As temperature and material loss increase, a significant visual transformation in the microstructure of the Stellite 20 ball surface is observed. Unlike the clean ball area presented in figure 1, the carbide and matrix boundaries are not well defined. Plastic deformation of the phases and/or the presence of a transfer layer are likely to have contributed to this. This is observed from the $20^{\circ} \mathrm{C}$ test through to the $200^{\circ} \mathrm{C}$, at which point, the transformation becomes uniform in appearance. 


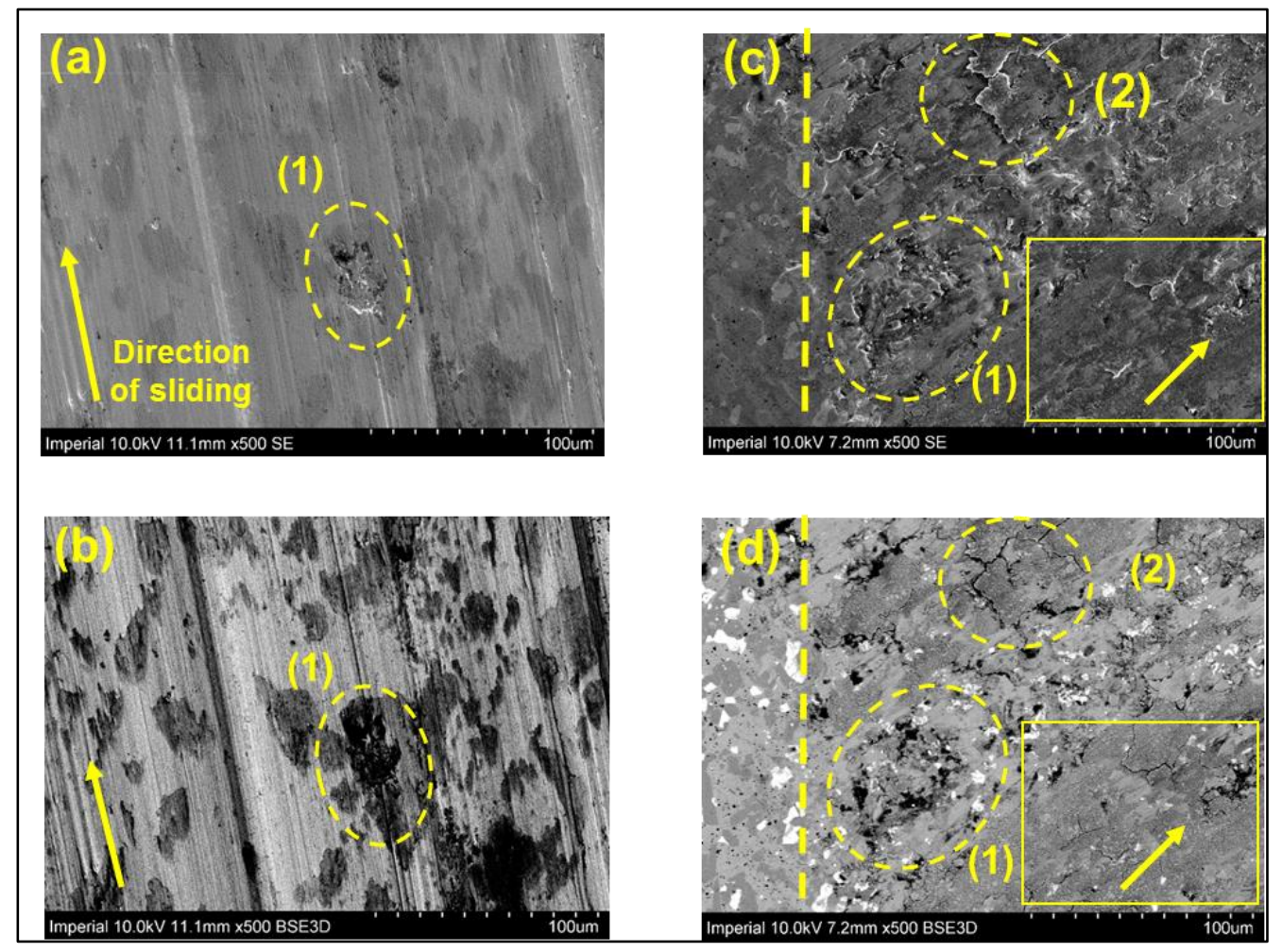

Figure 9: (a) and (b) area within disc wear track and (c) and (d) area within ball wear scar from using SE and BSE modes of the SEM of components tested under $35 \mathrm{~N}$ at $20^{\circ} \mathrm{C}$

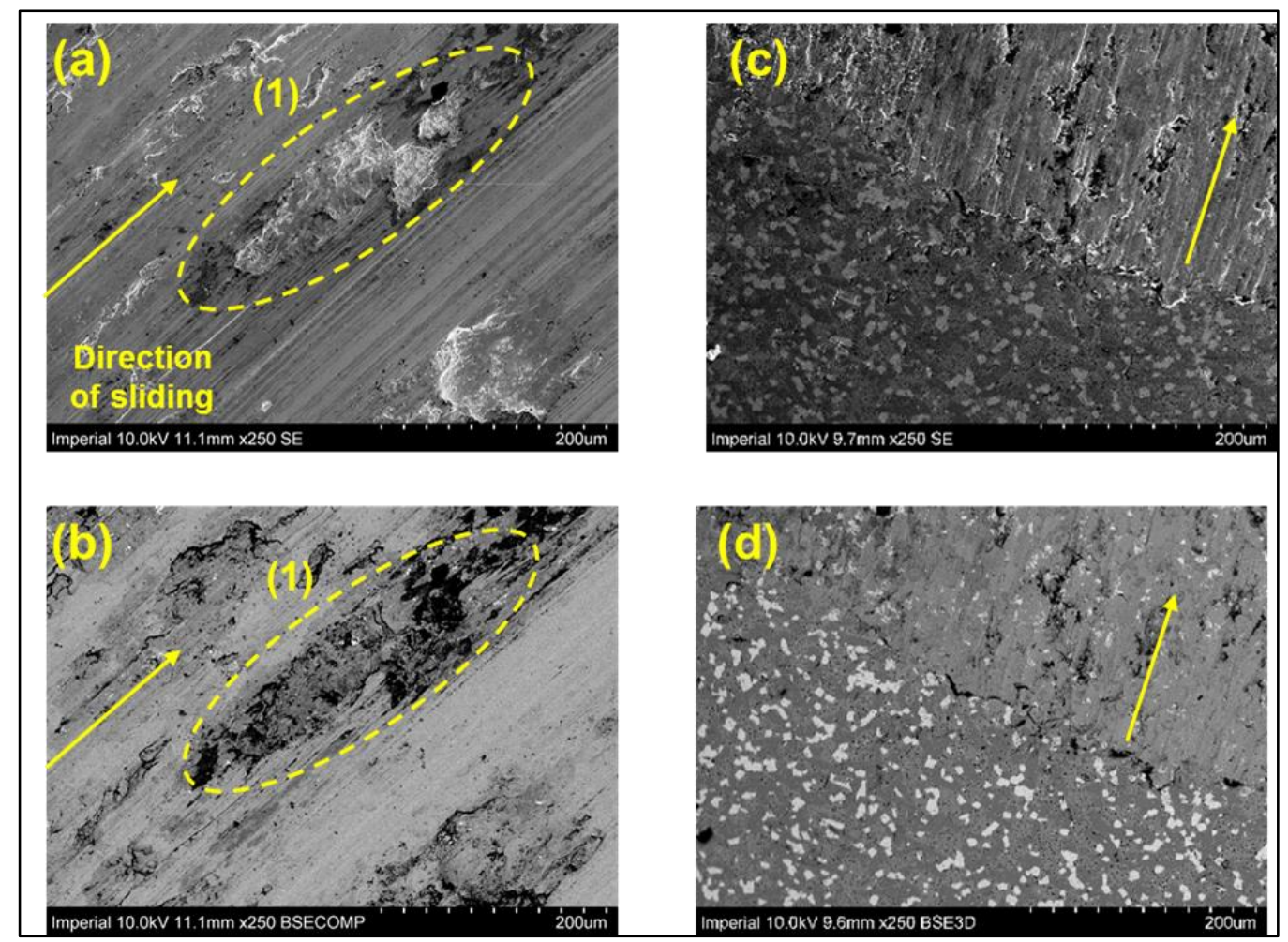

Figure 10: (a) and (b) area within disc wear track and (c) and (d) area within ball wear scar using $\mathrm{SE}$ and BSE modes of the SEM of components tested under $35 \mathrm{~N}$ at $100^{\circ} \mathrm{C}$ 

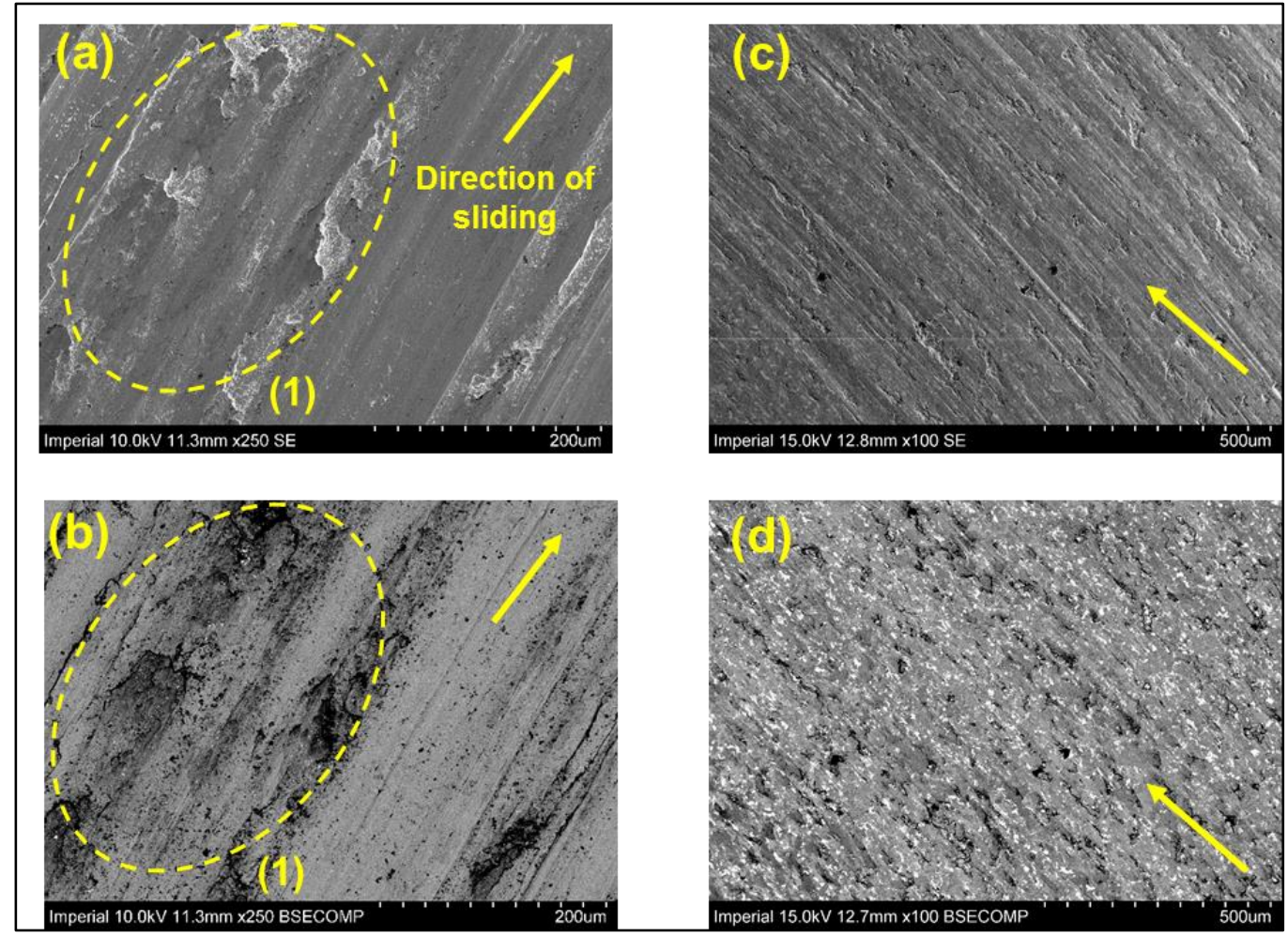

Figure 11: (a) and (b) area within disc wear track and (c) and (d) area within ball wear scar using SE and BSE modes of the SEM of components tested under $35 \mathrm{~N}$ at $200^{\circ} \mathrm{C}$ 


\begin{tabular}{|c|c|c|c|c|c|c|c|c|c|c|c|}
\hline 18 & & & Carbon & Oxygen & Chromium & Molybdenum & Iron & Cobalt & Nickel & Tungsten & Total \\
\hline Test: 35N @ 20 ${ }^{\circ} \mathrm{C}$ & Figure & Feature & $\%$ wt & $\%$ wt & $\%$ wt & $\% \mathrm{wt}$ & $\% \mathrm{wt}$ & $\%$ wt & $\%$ wt & $\%$ wt & $\% \mathrm{wt}$ \\
\hline \multirow[t]{5}{*}{ Disc } & 9 (a) and (b) & & & & & & & & & & \\
\hline & & Average track spectrum & 4 & 2 & 21 & 2 & 1 & 47 & 8 & 15 & 100 \\
\hline & & Transfer layer & 9 & 6 & 16 & 2 & 1 & 44 & 9 & 13 & 100 \\
\hline & & Scratches & 13 & 0 & 17 & 1 & 2 & 44 & 8 & 15 & 100 \\
\hline & & Feature (1) & & & & & & & & & \\
\hline \multicolumn{12}{|l|}{ Ball } \\
\hline & 9 (c) and (d) & & & & & & & & & & \\
\hline & & Average scar spectrum & 8 & 15 & 23 & 1 & 1 & 33 & 5 & 14 & 100 \\
\hline & & Feature(2) & 7 & 29 & 22 & 0 & 1 & 26 & 1 & 14 & 100 \\
\hline & & Medium grey area & 6 & 16 & 21 & 0 & 1 & 37 & 6 & 13 & 100 \\
\hline Test: 35N @ 100 ${ }^{\circ} \mathrm{C}$ & Figure & Feature & & & & & & & & & \\
\hline \multirow[t]{5}{*}{ Disc } & 10 (a) and (b) & & & & & & & & & & \\
\hline & & Average track spectrum & 6 & 1 & 19 & 2 & 2 & 46 & 9 & 15 & 100 \\
\hline & & Transfer layer & 4 & 6 & 17 & 0 & 0 & 50 & 10 & 13 & 100 \\
\hline & & Within grooves & 9 & 0 & 20 & 0 & 0 & 45 & 9 & 17 & 100 \\
\hline & & Feature (1) & 6 & 6 & 21 & 0 & 0 & 45 & 6 & 16 & 100 \\
\hline \multirow[t]{3}{*}{ Ball } & 10 (c) and (d) & & & & & & & & & & \\
\hline & & Average scar spectrum & 9 & 6 & 26 & 1 & 2 & 38 & 4 & 14 & 100 \\
\hline & & Within grooves & 7 & 6 & 26 & 0 & 1 & 41 & 3 & 16 & 100 \\
\hline Test: 35N@ 200 ${ }^{\circ} \mathrm{C}$ & Figure & Feature & & & & & & & & & \\
\hline \multirow[t]{5}{*}{ Disc } & 11 (a) and (b) & & & & & & & & & & \\
\hline & & Average track spectrum & 4 & 2 & 20 & 2 & 2 & 47 & 8 & 15 & 100 \\
\hline & & Within grooves & 4 & 0 & 20 & 2 & 1 & 49 & 9 & 15 & 100 \\
\hline & & Transfer layer & 3 & 3 & 20 & 1 & 2 & 47 & 9 & 15 & 100 \\
\hline & & Feature (1) & 6 & 6 & 22 & 0 & 1 & 43 & 7 & 15 & 100 \\
\hline \multirow[t]{2}{*}{ Ball } & 11 (a) and (b) & & & & & & & & & & \\
\hline & & Average scar spectrum & 9 & 15 & 27 & 0 & 2 & 35 & 0 & 12 & 100 \\
\hline
\end{tabular}

Table 4: EDX chemical compositional analysis of specific locations on disc wear track and ball wear scar surfaces for areas presented in figures 9, 10 and 11. 


\subsection{Wear prediction model}

\subsubsection{Semi analytical model}

The semi analytical model has been applied to each test, to compute the final maximum wear depth on both the ball and disc. The disc wear track width and the ball scar diameter are also computed. Figures 12 and 13 illustrate the comparison between the theoretical values computed and the actual final values measured on the post experimental test components.

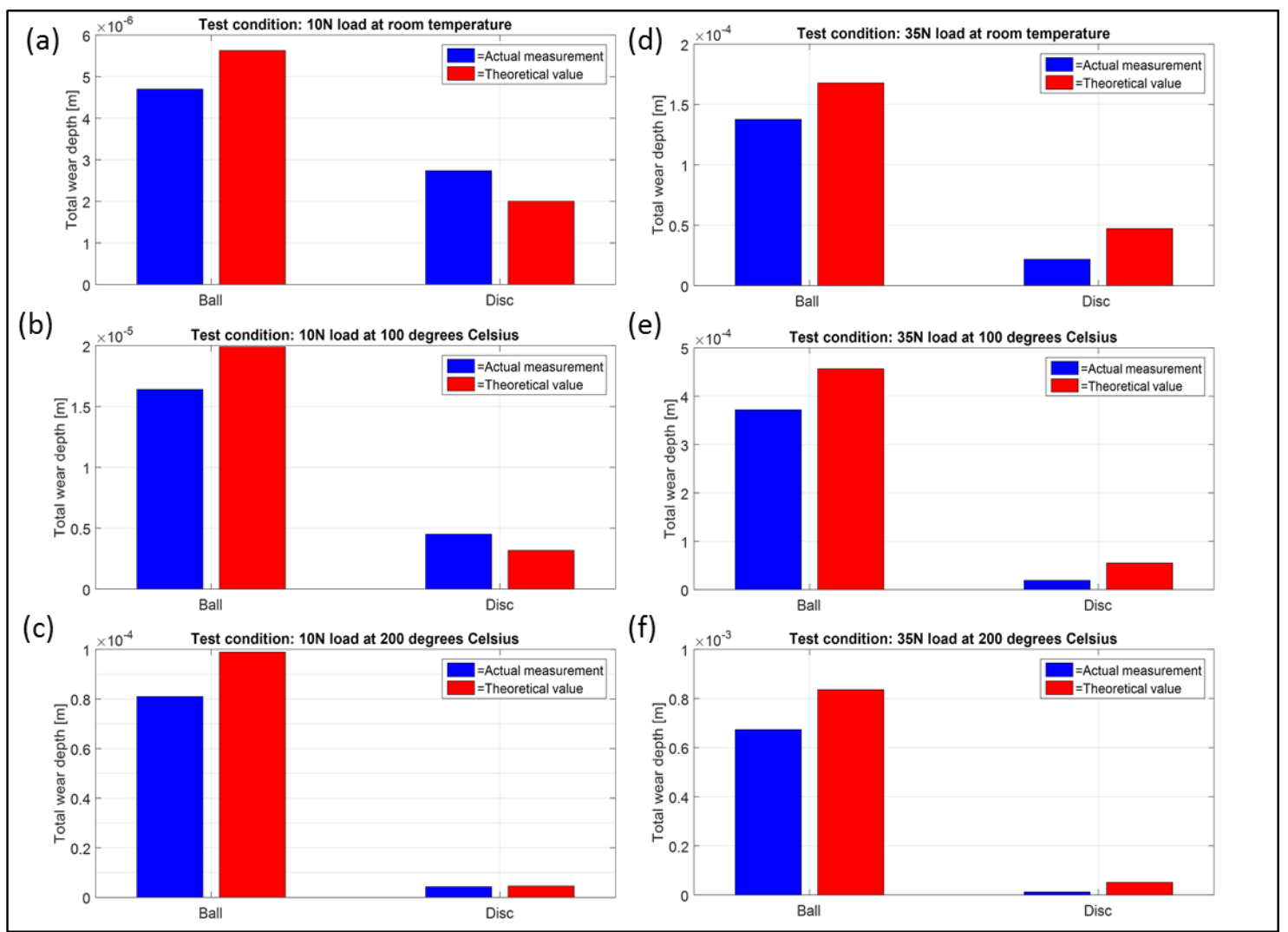

Figure 12 (a) - (f): results from the wear depth computed by the semi analytical model are compared to the results measured from the post experiment components

The results presented in Figure 12 show that the wear depth predicted is in good qualitative agreement with experimental measurements for the total wear depth. This is an expected outcome as it is the experimental data obtained that is used to calculate the wear coefficient used to predict wear using Archard's wear law, see section 2.4 .

The percentage error calculated between the measured and theoretical ball wear depth remained below $20 \%$ under all test conditions. The same for the track depth on the disc surface was far greater, with an average of $47 \%$ and standard deviation of $25 \%$ compared with the $1 \%$ calculated for the ball depth values.

The method by which the actual wear depth values were measured was different for the ball and disc component which may explain this spread, see Section 2.3.2. As described, the volume per track width is found using the white light interferometer at several points along the track and used to find the total volume lost over entire track length. This gives a good estimation of the material ploughed from the disc surface however, it is not guaranteed that this material removal is done uniformly or smoothly. This is evident from looking at the profiles in figures 5- 
7, where unevenness or roughness can be clearly seen in the surface profiles generated. The semi analytical model does not take this uneven material removal into account.

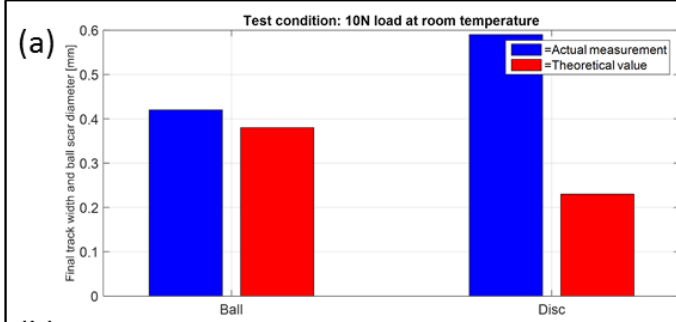

(b)

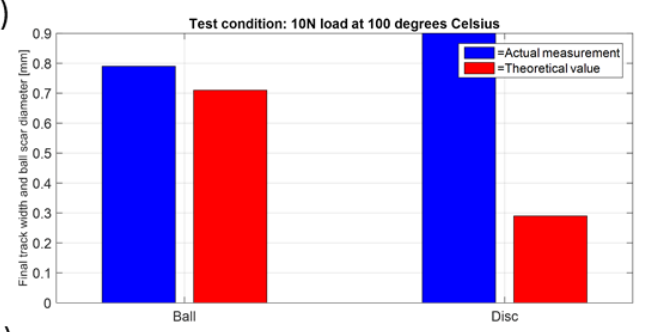

(c)

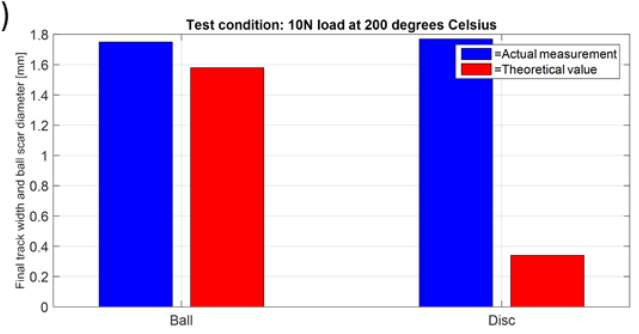

(d)

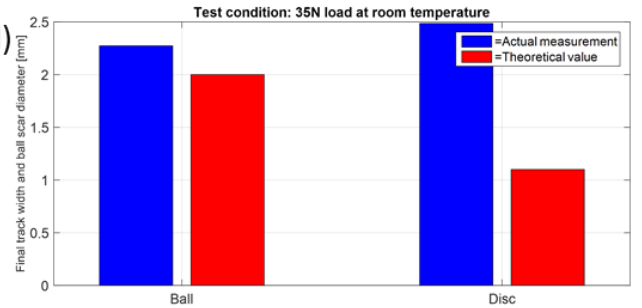

(e)

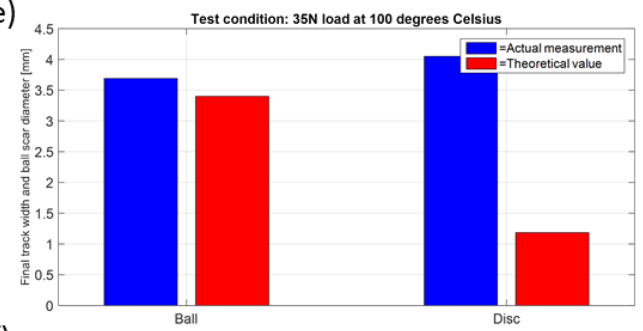

(f)

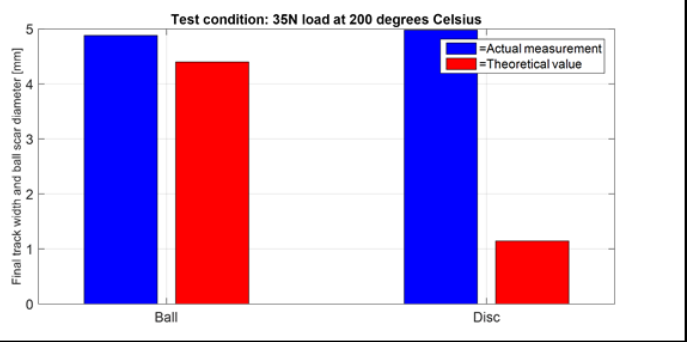

Figure 13 (a) - (f) Experimental disc width and ball scar diameter comparison with results from semi analytical wear prediction model at all testing conditions

Figure 13 presents the final track width and ball scar diameter measured using images in figures 5-7. These empirical values are compared to the values predicted by the semi analytical model. The values compared for the ball scar diameter are in good quantitative agreement, with an average percentage error of approximately $11 \%$ observed. The values compared for the disc track do not exhibit this agreement and do not provide a good qualitative or quantitative prediction. The ball scars observed were often flat and smooth in appearance. In general, the material on the ball surface appeared to be removed more smoothly than for the disc wear track. As for Figure 12, the inconsistency in the track wear prediction may be attributed to the non-uniform ploughing of Haynes 25 by the Stellite 20 ball, which results in grooved surfaces -see figures 5, 6 and 7 (d)), and therefore violate the modelling assumption of smoothly evolving surfaces. This is obviously more significant for the tests performed at $35 \mathrm{~N}$ than those at $10 \mathrm{~N}$-see figures 5, 6 and 7 (b)). In order for the model to be improved the change in surface roughness should be explicitly captured.

\subsection{Conclusion}

In this article the sliding wear behaviour of two cobalt based alloys are examined using a ball on disc experimental apparatus for a range of environmental conditions set to simulate the primary loop of a nuclear reactor. It was shown that overall wear volume increases with both an increase in temperature and load. Interestingly the ball and disc component did not follow the same wear trend under each of the two load conditions. The ball wear increased with increased temperature for both loading conditions, significantly so at the highest temperature. Under the lower loading condition the same trend was observed for disc wear; an increase in volume measured resulting from an increase in temperature. While the disc wear did increase with increased temperature from $20^{\circ} \mathrm{C}$ to $100^{\circ} \mathrm{C}$ 
under the higher loading condition, the wear volume measured for the $200^{\circ} \mathrm{C}$ was slightly reduced compared to the $100^{\circ} \mathrm{C}$ disc volume.

Topographical and compositional analysis also revealed different manifestations of wear on the test components over the temperature and load range. This work has been successful in presenting a picture of how the wear of the alloys are impacted by load and temperature in conditions reproducing nuclear reactor conditions. The compositional analysis revealed interesting results on the material surface, such as the identification of oxygen within the ball scar and wear track implying the presence of an oxide formation on one or both of the components. Future work may include the identification of what is present using Raman spectroscopy or cross sectional EDX analysis of the samples. Using a torque meter to measure the changing friction throughout the sliding interaction would also be a useful tool to increase the value of experimental data and track the evolution of the frictional response in time, which could be correlated with different wear mechanisms and provide information about changes in wear regimes during the tests in the absence of intermediate wear scar analysis.

In addition to the empirical wear analysis, a semi analytical wear prediction model was presented and compared using experimentally obtained data. The model prediction was in fairly good agreement with the experiments for the total wear depth of the test components disc track and ball scar. It is limited in that assumptions are made in the model such as the uniform removal of material per cycle. From figures 5-11 it can be seen clearly that material is not removed entirely evenly from the component surfaces as assumed by the model. EDX analysis also identified some material transfer between the test components, not accounted for in the semi analytical model results. There is scope to develop a more accurate numerical model (based on more computationally demanding simulations performed using the finite element method - FEM) to which other variables could be added, such as the formation and removal of a protective oxide layer on the material surface, and important geometrical parameters could also be considered.

\section{Acknowledgments}

RM, DD and PS acknowledge the financial support of Rolls-Royce Plc. DD also acknowledges the support of the Engineering and Physical Sciences Research Council (EPSRC) through the Established Career Fellowship EP/N025954/1.

\section{References}

1. Freund, G.A., Materials for Control Rod Drive Mechanisms. 1963.

2. Ocken, H., Reducing the cobalt inventory in light water reactors. Nuclear Technology, 1984. 68: p. 18-28.

3. Amateau, M.F. and W.A. Glaeser, Survey of materials for high-temperature bearing and sliding applications. Wear, 1964. 7(5): p. 385-418.

4. Crook, P., Cobalt and Cobalt Alloys. ASM Handbook. 1990.

5. Ahmed, R., et al., Single asperity nanoscratch behaviour of HIPed and cast Stellite 6 alloys. Wear, 2014. 312(1-2): p. 70-82.

6. Chen, J., et al., Improving the wear properties of Stellite 21 alloy by plasma surface alloying with carbon and nitrogen. Wear, 2008. 264(3-4): p. 157-165.

7. Gholipour, A., M. Shamanian, and F. Ashrafizadeh, Microstructure and wear behavior of stellite 6 cladding on 17-4 PH stainless steel. Journal of Alloys and Compounds, 2011. 509(14): p. 4905-4909. 
8. Inman, I.A., S.R. Rose, and P.K. Datta, Studies of high temperature sliding wear of metallic dissimilar interfaces II: Incoloy MA956 versus Stellite 6. Tribology International, 2006. 39(11): p. 1361-1375.

9. Lashgari, H.R., S. Zangeneh, and M. Ketabchi, Isothermal aging effect on the microstructure and dry sliding wear behavior of $\mathrm{Co}-28 \mathrm{Cr}-5 \mathrm{Mo}-0.3 \mathrm{C}$ alloy. Journal of Materials Science, 2011. 46(22): p. 7262-7274.

10. Pauschitz, A., M. Roy, and F. Franek, Mechanisms of sliding wear of metals and alloys at elevated temperatures. Tribology International, 2008. 41(7): p. 584-602.

11. Radu, I. and D.Y. Li, Investigation of the role of oxide scale on Stellite 21 modified with yttrium in resisting wear at elevated temperatures. Wear, 2005. 259(1-6): p. 453-458.

12. Sebastiani, M., et al., Wear mechanisms and in-service surface modifications of a Stellite $6 B$ Co-Cr alloy. Wear, 2012. 290-291: p. 10-17.

13. Wood, P.D., H.E. Evans, and C.B. Ponton, Investigation into the wear behaviour of Stellite 6 during rotation as an unlubricated bearing at $600{ }^{\circ} \mathrm{C}$. Tribology International, 2011. 44(12): p. 1589-1597.

14. Yao, M.X., et al., Metallographic study and wear resistance of a high-C wrought Co-based alloy Stellite 706K. Materials Science and Engineering: A, 2005. 407(1-2): p. 291-298.

15. Yu, H., R. Ahmed, and H. de Villiers Lovelock, A Comparison of the Tribo-Mechanical Properties of a Wear Resistant Cobalt-Based Alloy Produced by Different Manufacturing Processes. Journal of Tribology, 2007. 129(3): p. 586-594.

16. $\mathrm{Yu}, \mathrm{H}$., et al., Influence of Manufacturing Process and Alloying Element Content on the Tribomechanical Properties of Cobalt-Based Alloys. Journal of Tribology, 2008. 131(1): p. 011601-011601.

17. Zhang, K., Effects of test conditions on the tribological behaviour of a journal bearing in molten zinc. Wear, 2005. 259(7-12): p. 1248-1253.

18. Ahmed, R., et al., Influence of Re-HIPing on the structure-property relationships of cobaltbased alloys. Tribology International, 2013. 57: p. 8-21.

19. Ishida, T., Imayoshi, S., Yoritsune, T., Nunokawa, H., Ochiai, M., Ishizaka, Y., Development of in-vessel type control rod drive mechanism for marine reactor. Journal of NUCLEAR SCIENCE and TECHNOLOGY, 2001. 38(7): p. 557-570.

20. SKF. Bearing failures and their causes: Wear. Bearing Failures and their causes [Website article] 2016 [cited 2016 03/08/16]; http://www.skf.com/cn/en/products/bearings-unitshousings/roller-bearings/principles/troubleshooting/bearing-failures-and-theircauses/bearing-damage/wear/index.html:[Article on SKF.com describing wear manifests in rolling bearings].

21. El-Thalji, I. and E. Jantunen, A descriptive model of wear evolution in rolling bearings. Engineering Failure Analysis, 2014. 45: p. 204-224.

22. Hegadekatte, V., et al., A predictive modeling scheme for wear in tribometers. Tribology International, 2008. 41(11): p. 1020-1031.

23. Blau, P.J., Fifty years of research on the wear of metals. Tribology International, 1997. 30(5): p. 321-331.

24. Hegadekatte, V., Huber, N., Kraft, O., Modeling and simulation of wear in a pin on disc tribometer. Tribology Letters, 2006. 24(1): p. 51-60.

25. Lim, S.C. and M.F. Ashby, Wear-mechanism maps. Acta Metallurgica, 1987. 35(1): p. 1-24.

26. Knezevic, M.C., J. S.; Lovato, M. L.; McCabe, R. J., Deformation behaviour of the cobalt-based superalloy Haynes 25: Experimental characterization and crystal plasticity modeling. Acta Materialia, 2014. 63: p. 162-168.

27. Liu, R., Yao, J.H., Zhang, Q.L., Yao, M.X., Collier, R., Sliding wear and solid-particle erosion resistance of a novel high-tungsten Stellite alloy. Wear, 2014. 322-323: p. 41-50.

28. Motallebzadeh, A., Atar, E., Cimenoglu, H., Sliding wear characteristics of molybdenum containing Stellite 12 coating at elevated temperatures. Tribology International, 2015. 91: p. 40-47.

29. Johnson, K.L., Contact Mechanics. 1985, Cambridge: Cambridge University Press. 
30. Blank, H., Hall, A. M., Hackson, J. W., Anderson, W. K., The heat treatment and working of Haynes 25 alloy. 1953: United States Atomic Energy Commission. 